\title{
Crystallization Morphology Regulation on Enhancing Heat Resistance of Polylactic Acid
}

\author{
Yufei Liu ${ }^{1,2}$, Siyuan Jiang ${ }^{1}$, Wei Yan ${ }^{3}$, Min He ${ }^{1, *}$, Jun Qin ${ }^{1}$, Shuhao Qin ${ }^{2}$ and Jie Yu ${ }^{2, *}$ \\ 1 Department of Polymer Material and Engineering, College of Materials and Metallurgy, Guizhou University, \\ Guiyang 550025, China; gs.liuyf16@gzu.edu.cn (Y.L.); gs.syjiang18@gzu.edu.cn (S.J.); qi_njun@163.com (J.Q.) \\ 2 National Engineering Research Center for Compounding and Modification of Polymeric Materials, \\ Guiyang 550014, China; pec.shqin@gzu.edu.cn \\ 3 School of Chemistry and Materials, Guiyang University, Guiyang 550005, China; lrasyw@163.com \\ * Correspondence: mhe@gzu.edu.cn (M.H.); pec.jyu@gzu.edu.cn (J.Y.)
}

Received: 4 June 2020; Accepted: 12 July 2020; Published: 15 July 2020

\begin{abstract}
To expand the use of polylactic acid (PLA) in high-temperature environments, crystallization morphology regulation was studied to enhance the heat resistance of PLA. PLA crystallinity was controlled using heat treatment and nucleating agent (zinc phenylphosphonate, brand TMC). The heat deflection temperatures of PLAs with same crystallinities considerably varied using different treatments. The crystallization morphology of PLA (4032D) and PLA/TMC composites was studied using X-ray diffraction (XRD) and polarized optical microscopy. XRD test results show that TMC can improve the crystallization rate and heat treatment can enhance the crystallinity and thickness of PLA, suggesting that the crystallization morphology improved after heat treatment. Nucleating agents can increase the crystallinity of PLA but cannot improve its crystallization morphology. The findings indicate that at the same crystallinity, PLAs exhibit improved crystallization morphology and high heat resistance; these results can provide guidance for improving the heat resistance of PLAs and facilitate the design of new nucleating agents.
\end{abstract}

Keywords: polylactic acid; crystallization morphology; heat resistance

\section{Introduction}

Polylactic acid (PLA) has attracted considerable research interest owing to its good biocompatibility and biodegradability [1-7]. However, its disadvantages, such as poor heat-deflection temperature (HDT: $50{ }^{\circ} \mathrm{C}$ for neat PLA) and slow crystallization rate, limit its application [8-13]. HDT is a crucial physical quantity used to characterize the heat resistance of polymeric materials [14,15]. Therefore, extensive research has been conducted to improve the heat resistance of PLAs [16] (Table 1). In recent years, lignin (LG) [17], cellulose nanocrystals (CNCs) [18], glass fiber (GF) [19], corn fiber (CF) [20], D-lactide [21], short Kenaf fiber (KF) [22], and alloys [23-29] have been used to increase the HDT of PLAs through substantial research $[30,31]$. 
Table 1. Research progress on the heat deflection temperature (HDT) of polylactic acid (PLA).

\begin{tabular}{ccccc}
\hline PLA and Its Composites & HDT $\left({ }^{\circ} \mathbf{C}\right)$ & Test Method & Heat Treatment & References \\
\hline PLA & 50 & $0.45 \mathrm{MPa}$ & No & {$[16]$} \\
PLA/LG $(20 \%)$ & 54 & $0.45 \mathrm{MPa}$ & No & {$[17]$} \\
PLA/CNC $(20 \%)$ & 78 & DMA & Yes, at $130{ }^{\circ} \mathrm{C}$ & {$[18]$} \\
PLA/GF $(40 \%)$ & 55 & $1.82 \mathrm{MPa}$ & No & {$[19]$} \\
PLA/GF $(20 \%)$ & 150 & $0.45 \mathrm{MPa}$ & Yes, at $100{ }^{\circ} \mathrm{C}$ & {$[32]$} \\
PLA/CF $(10 \%)$ & 60 & $1.82 \mathrm{MPa}$ & No & {$[20]$} \\
PLA/KF $(40 \%)$ & 135 & $0.45 \mathrm{MPa}$ & Yes, at $80{ }^{\circ} \mathrm{C}$ & {$[22]$} \\
PLA/D-lactide $(0.5 \mathrm{wt} \%)$ & 150 & $0.45 \mathrm{MPa}$ & Yes, at $140{ }^{\circ} \mathrm{C}$ & {$[21]$} \\
PLA/PHA & 62 & $1.82 \mathrm{MPa}$ & Yes, at $100{ }^{\circ} \mathrm{C}$ & {$[24]$} \\
$(90 / 10) P L A / P H A$ & 50 & $1.82 \mathrm{MPa}$ & No & {$[24]$} \\
PLA/PP $(60 / 40)$ & 60 & $0.45 \mathrm{MPa}$ & No & {$[26]$} \\
PLA/POM $(40 / 60)$ & 140 & $0.46 \mathrm{MPa}$ & No & {$[29]$} \\
\hline
\end{tabular}

Using heat-treatment, Wang [32] studied the thermal resistance of GF-reinforced PLA composites and found that enhanced crystallization post heat treatment significantly improves the mechanical properties of neat PLA and PLA/GF composites. Pan [33] studied the HDT of PLA/short basalt fiber (SBF) composites and found that PLA/SBF composites comprising interfacial crystals exhibit a significantly higher overall HDT than neat PLA. Lin [34] increased the HDT of PLAs by incorporating polycarbonate (PC) into PLA and using annealing to accelerate the crystallization of the PLA phase; consequently, the increase in HDT was attributed to the formation of a rigid three-dimensional (3D) framework comprising rigid PC particles and PLA crystals in the PLA/PC blends. These studies indicate that the modification of PLA using fiber, PC or nucleating agents must undergo heat treatment to improve the HDT. Moreover, crystallinity improvement is a prerequisite for improving the HDT of PLA. However, these studies did not consider the effect of crystal morphology on thermal stability. Our recent research shows that thermal stability is not only associated with the crystallinity of PLA, but also to its crystallization morphology.

In this study, a set of experiments were conducted to study the impact of a nucleating agent and heat treatment on improving the crystallinity, crystallization morphology and HDT of PLA. The crystallization morphology regulation for enhancing the heat resistance of PLA was analyzed using differential scanning calorimetry (DSC), X-ray diffraction (XRD) characterization and polarized optical microscopy (POM). Our work indicates that at the same crystallinity, a more complete crystallization morphology corresponds to a better heat resistance of PLA; these findings provide guiding significance for improving the heat resistance of PLA and designing a new nucleating agent.

\section{Experimental section}

\subsection{Materials and Sample Preparation}

An extrusion molding grade of PLA, 4032D, was supplied by Natureworks (Blair, NE, USA). PLA has a density of $1.24 \mathrm{~g} \mathrm{~cm}^{-3}$ and glass transition temperature $(\mathrm{Tg})$ of $60{ }^{\circ} \mathrm{C}$. The average molecular weight $\left(M_{\mathrm{W}}\right)$ and numerically average molecular weight $\left(M_{\mathrm{n}}\right)$ of PLA is $100 \mathrm{~kg} / \mathrm{mol}$ and $58 \mathrm{~kg} \mathrm{~mol}^{-1}$, respectively. Commercial zinc phenylphosphonate (brand TMC) (Figure 1), a white powder, was purchased from Shanxi Chemical Research Institute Co., Ltd. (Jinzhong, Shanxi, China), and it has a melting point of $300^{\circ} \mathrm{C}$.

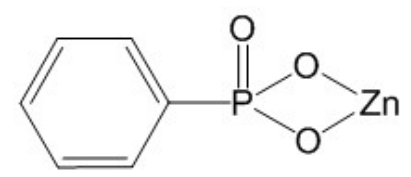

Figure 1. Chemical structure of zinc phenylphosphonate (brand TMC). 
Both PLA and TMC were dried at $80^{\circ} \mathrm{C}$ for $24 \mathrm{~h}$ in a vacuum oven. PLA in pellet form and white powder TMC ( $0.3 \mathrm{wt} \%$ and $0.5 \mathrm{wt} \%$, respectively) were compounded using a twin-screw extruder (LHFD1-130718, Lab Tech Engineering Company, Ltd. Samutprakarnc, Thailand) with a screw diameter of $16 \mathrm{~mm}$ and length-to-diameter ratio of 40 . The temperature interval in various zones from the hopper to die was set at $5^{\circ} \mathrm{C}$ in the range of $165^{\circ} \mathrm{C}-210^{\circ} \mathrm{C}$. The rotational speed of the screw was set at $100 \mathrm{rpm}$. Post extrusion, the strands were cooled with cold water and granulated with a granulator thereafter.

After blending, the PLA and PLA/TMC materials were again dried at $80^{\circ} \mathrm{C}$ for $12 \mathrm{~h}$ to remove any residual moisture. Thereafter, the blends were injected into standard splines on an injection molding machine (PL860/290v, Wuxi Haitian Machinery Co. LTD, Jiangsu, China) at $210{ }^{\circ} \mathrm{C}$ for HDT, XRD, DSC and POM testing. The injection speed, packing pressure and packing time were set as $55 \mathrm{~cm}^{3} / \mathrm{s}$, $5.0 \mathrm{MPa}$ and $20.0 \mathrm{~s}$, respectively.

To obtain samples with different crystallinities, the PLA (4032D) samples were treated at $110^{\circ} \mathrm{C}$ for 20 and $30 \mathrm{~min}$. The heat treatment durations of 20 and $30 \mathrm{~min}$ are deduced from our preliminary research.

\subsection{Heat Deflection Temperature (HDT)}

The effect of crystallinity on the HDT of PLA was determined using an HDT \& VICAT testing machine (ZWK1000, MTS Systems (China) Co. LTD, Shenzhen, China). The measurements were performed according to GB/T1634.1-2004 with a constant load of $0.45 \mathrm{MPa}$ and temperature rate of $120^{\circ} \mathrm{Ch}^{-1}$.

\subsection{Bending Modulus}

The bending modulus was tested according to GB/T9341-2008 with a bending rate of $2 \mathrm{~mm} \mathrm{~min}^{-1}$, fixture spacing of $80 \mathrm{~mm}$, and using the average value of each group containing five samples.

\subsection{Storage and Loss Moduli}

Storage and loss modulus measurements were performed on a Q800 dynamic mechanical analysis instrument (DMA; TA Instruments, New Castle, DE, USA) at $1 \mathrm{~Hz}$ at a heating rate of $2{ }^{\circ} \mathrm{C} \min ^{-1}$ in a temperature range of $30^{\circ} \mathrm{C}-120^{\circ} \mathrm{C}$. The high-temperature measurements were performed under a stream of dry $\mathrm{N}_{2}$.

\subsection{Differential Scanning Calorimetric (DSC) Analysis}

A Q20 DSC (TA Instruments, New Castle, DE, USA) was used to analyze the crystallization of heat-treated and untreated injection-molded PLA and PLA/TMC specimens. For a typical DSC test, a sample with a weight of approximately $2-4 \mathrm{mg}$ was cut from the PLA specimen. Thereafter, the samples were heated to $210^{\circ} \mathrm{C}$ at a rate of $10^{\circ} \mathrm{C} \mathrm{min}{ }^{-1}$, held for $3 \mathrm{~min}$ to eliminate previous thermal history and cooled to $40^{\circ} \mathrm{C}$ at a rate of $2{ }^{\circ} \mathrm{C} \mathrm{min}-1$ under $\mathrm{N}_{2}$ atmosphere. Based on the thermograms obtained from the first heating scan, the degree of crystallinity $\left(X_{\mathrm{c}}\right)$ of the sample was calculated as follows:

$$
X_{\mathrm{c}}=\Delta H_{\mathrm{m}} /\left((1-\mathrm{x}) \Delta H_{\mathrm{m}}^{0}\right)
$$

where $\Delta H_{\mathrm{m}}$ represents the crystallization enthalpy of the sample $\left(\mathrm{J} \mathrm{g}^{-1}\right) ; \Delta H_{\mathrm{m}}^{0}$ represents the enthalpy value of melting a $100 \%$ crystalline form of PLA, which is $93 \mathrm{~J} \mathrm{~g}^{-1}$; and $\mathrm{x}$ represents the weight fraction of TMC. To calculate the apparent activation energy of PLA and PLA/TMC $(0.5 \mathrm{wt} \%)$, the samples were heated to $210{ }^{\circ} \mathrm{C}$ at a rate of $10^{\circ} \mathrm{C} \mathrm{min}-1$, held for $3 \mathrm{~min}$ to eliminate previous thermal history and cooled to $40{ }^{\circ} \mathrm{C}$ at rates of $1{ }^{\circ} \mathrm{C} \mathrm{min}^{-1}, 2^{\circ} \mathrm{C} \mathrm{min}^{-1}, 3^{\circ} \mathrm{C} \mathrm{min}^{-1}$ and $4{ }^{\circ} \mathrm{C} \mathrm{min}^{-1}$ under $\mathrm{N}_{2}$ atmosphere. 
Kissinger's method, which considers the variation of the crystallization peak temperature $\left(T_{p}\right)$ with the cooling rate $(\varphi)$, has been widely used to evaluate the overall effective energy barrier $(\Delta E)$. The Kissinger method is expressed as follows [35]:

$$
d\left(\ln \left(\varphi / T_{\mathrm{p}}^{2}\right)\right) / \mathrm{d}\left(1 / T_{\mathrm{p}}\right)=-\frac{\Delta E}{R}
$$

where $R(8.314)$ represents the gas constant. The slopes of the straight lines yield the value of $\Delta E / R$.

\subsection{X-ray Diffraction (XRD) Characterization}

The influence of TMC and heat treatment on the crystal form of PLA was examined on the Rigaku (Ultima-IV) diffractometer equipped with a $\mathrm{Cu}-\mathrm{K} \alpha$ radiation source at a scan angle range of $5^{\circ}-80^{\circ}$ and scan rate of $1^{\circ} \mathrm{min}^{-1}$. Based on the XRD profiles, the crystallinity of PLA samples was calculated using the following formula [36]:

$$
X_{\mathrm{c}}=I_{\mathrm{c}} /\left(I_{\mathrm{c}}+I_{\mathrm{a}}\right)
$$

where $I_{\mathrm{c}}$ and $I_{\mathrm{a}}$ represent the integrated intensities scattered over a suitable angular interval by the crystalline and amorphous phases, respectively.

The dimensions of the crystals can be calculated using the following formula [37]:

$$
(D=(\mathrm{K} \gamma) /(\mathrm{B} \cos \theta)
$$

where $\gamma=0.15406$ is the $\mathrm{X}$-ray wavelength, $K$ is the Scherrer constant $(K=0.89)$, and B is the half-peak width of the XRD peak.

\subsection{Polarized Optical Microscopy (POM)}

The evolution of the crystal structure of the samples was observed using an Axio Scope A1 HC302 polarized optical microscope (Carl Zeiss, Jena, Germany) and heating stage (Instec, inc., Boulder, CO, USA) equipped with a digital camera. The samples were placed between two glass plates, melted at $200{ }^{\circ} \mathrm{C}$ on a Linkam THMS600 hot stage for $3 \mathrm{~min}$ to eliminate the thermal history and cooled to room temperature. Hereafter, portions of the samples were heat treated in a vacuum drying oven at $110^{\circ} \mathrm{C}$ for $5 \mathrm{~min}$.

\section{Results and Discussions}

\subsection{Heat Deflection Temperature (HDT) and Moduli}

To evaluate the effects of the crystal morphology of PLA on its HDT, the HDT and moduli of PLA samples (treated at $110{ }^{\circ} \mathrm{C}$ under varying heat treatment durations of 20 and $30 \mathrm{~min}$ ) and PLA/TMC $(0.3 \mathrm{wt} \%$ and $0.5 \mathrm{wt} \%)$ composites were studied. As shown in Figure $2 \mathrm{a}$, the samples with various amounts of TMC $(0.3 \mathrm{wt} \%$ and $0.5 \mathrm{wt} \%)$ and no heat treatment show a similar HDT of approximately $50{ }^{\circ} \mathrm{C}$, which indicates an insignificant effect of the increased crystallinity by TMC on the HDT of PLA. Conversely, post heat treatment at $110^{\circ} \mathrm{C}$ for 20 and $30 \mathrm{~min}$, both samples exhibited drastically improved HDT. The HDT of heat-treated PLA is consistent with that reported in the literature [38]. In particular, with nearly the same crystallinity (as observed in Figure $2 \mathrm{a}$ and Table 2), the HDT of PLA heat treated at $110{ }^{\circ} \mathrm{C}$ for $30 \mathrm{~min}$ was $124.6^{\circ} \mathrm{C}$, demonstrating an increase of $136.9 \%$ compared with the HDT of PLA with $0.5 \mathrm{wt} \%$ TMC. Clearly, the substantially improved HDT was attributed to not only the significantly enhanced crystallinity, but also the complete morphology of the crystal. 
(a)

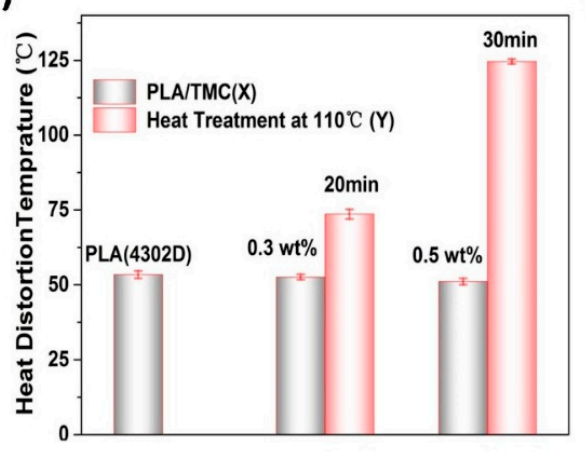

(c)

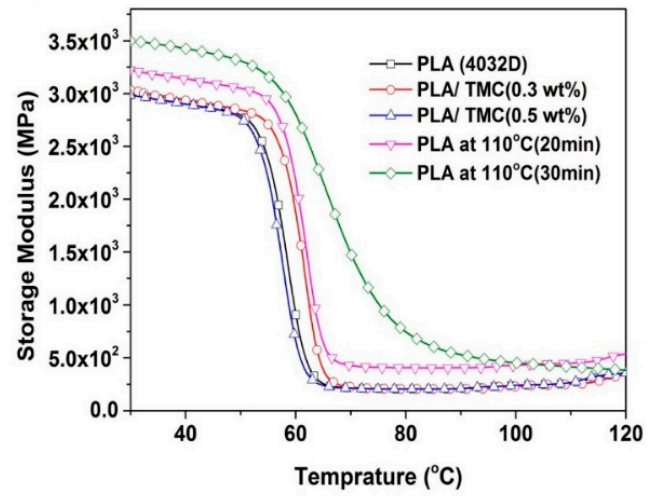

(b)

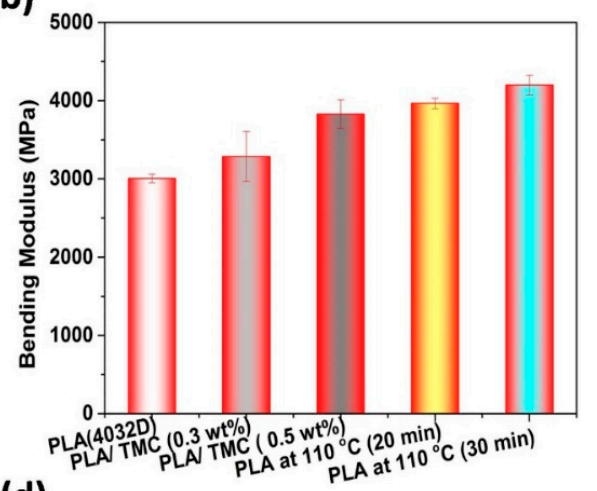

(d)

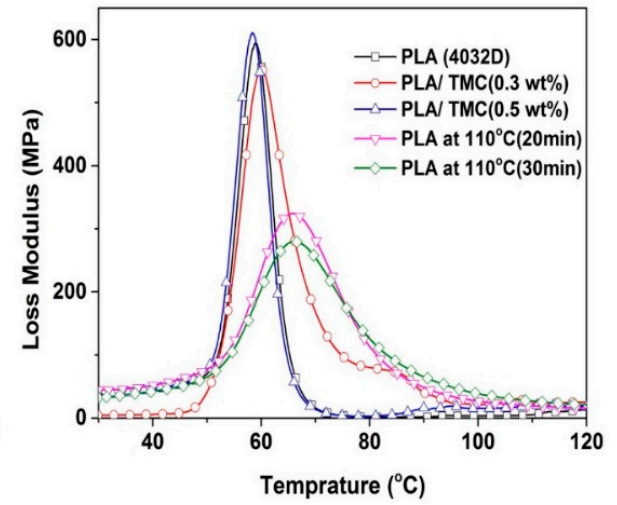

Figure 2. Heat-deflection temperature (HDT) and moduli of samples of neat PLA, PLA/TMC (0.3 wt $\%$ and $0.5 \mathrm{wt} \%$ ) composites and PLA treated at $110{ }^{\circ} \mathrm{C}$ under varying heat treatment durations (20 and 30 min): (a) HDT, (b) bending modulus, (c) storage modulus, (d) loss modulus.

In HDT testing, a specific load is applied to the polymer material, after which the temperature is increased at a certain rate to reach the corresponding temperature where the specified deformation is reached. The test principles of HDT and the bending, storage and loss moduli have something in common, e.g., their test methods use the simply supported beam pressure. Therefore, the modulus of PLA samples was also examined for an in-depth analysis of HDT. Figure $2 b-d$ shows that the bending and storage moduli of heat-treated PLA was higher than those of PLA/TMC composites and neat PLA. These findings are consistent with those obtained in Ikada's report [39]. The loss modulus of heat-treated PLA was lower than that of PLA and PLA/TMC composites. The modulus test results show that the rigidity of heat-treated PLA was stronger than that of PLA and PLA/TMC composites [15]. The HDT results were verified through the results of bending and storage moduli. To illustrate the relationship between crystallization and HDT, the crystallinity, crystal type and crystal size of PLA were processed using different testing protocols: DSC, XRD and POM.

Table 2. Differential scanning calorimetric (DSC) parameters and HDT of PLA samples.

\begin{tabular}{|c|c|c|c|c|c|c|}
\hline Samples & $\begin{array}{c}X_{\mathrm{n}}{ }^{\mathrm{a}} \\
(\%)\end{array}$ & $\begin{array}{l}T_{0} \mathrm{~b} \\
\left({ }^{\circ} \mathrm{C}\right)\end{array}$ & $\begin{array}{l}T_{\mathrm{p}}{ }^{\mathrm{c}} \\
\left({ }^{\circ} \mathrm{C}\right)\end{array}$ & $\begin{array}{c}\Delta H^{\mathrm{d}} \\
(\mathrm{J} / \mathrm{g})\end{array}$ & $\begin{array}{l}T_{\mathrm{m}} \mathrm{e} \\
\left({ }^{\circ} \mathrm{C}\right)\end{array}$ & $\begin{array}{r}H D T \\
\left({ }^{\circ} \mathrm{C}\right)\end{array}$ \\
\hline PLA (4032D) & 11.7 & 113.7 & 94.5 & 10.9 & 168.0 & 53.4 \\
\hline PLA/TMC (0.3 wt\%) & 21.3 & 126.1 & 113.8 & 15.8 & 167.6 & 51.1 \\
\hline PLA at $110^{\circ} \mathrm{C}(20 \mathrm{~min})$ & 25.3 & 126.7 & 113.3 & 47.9 & 169.7 & 73.6 \\
\hline PLA/TMC (0.5 wt\%) & 30.1 & 139.1 & 136.3 & 28.02 & 167.5 & 52.6 \\
\hline PLA at $110^{\circ} \mathrm{C}(30 \mathrm{~min})$ & 30.84 & 139.0 & 135.9 & 43.3 & 167.7 & 124.6 \\
\hline
\end{tabular}

${ }^{\mathrm{a}}$ crystallinity; ${ }^{\mathrm{b}}$ onset crystallization temperature; ${ }^{\mathrm{c}}$ peak temperature of crystallization; ${ }^{\mathrm{d}}$ melting enthalpy; ${ }^{\mathrm{e}}$ melting temperature of the first crystal. 


\subsection{Differential Scanning Calorimetric (DSC)}

The crystallinity behaviors of PLA and PLA/TMC composites were investigated by DSC analysis. Figure 3 shows the DSC thermograms of PLA post different heat treatments and PLA/TMC composites during the first heating stage. All DSC curves of PLA/TMC composites exhibited a cold crystallization peak and peak temperature of the crystallization of PLA. The peak temperature of crystallization of PLA is approximately $94.5^{\circ} \mathrm{C}$, which increased to $113.8^{\circ} \mathrm{C}$ and $136.3^{\circ} \mathrm{C}$ after adding TMC in PLA in $0.3 \mathrm{wt} \%$ and $0.5 \mathrm{wt} \%$ concentrations, respectively. Compared with neat PLA, the peak temperature of crystallization $\left(113.8^{\circ} \mathrm{C}\right.$ and $\left.136.3^{\circ} \mathrm{C}\right)$ and crystallinity $(21.3 \%$ and $30.1 \%)$ of PLA/TMC composites calculated using formula (1) gradually increased. These results are consistent with those obtained by Han [40] and Wua [41]. With increasing heat treatment durations, the crystallinity $(21.3 \%$ and $30.1 \%$ ) of PLA (subjected to heat treatment at $110{ }^{\circ} \mathrm{C}$ for 20 and $30 \mathrm{~min}$ ) calculated using formula (1) in terms of thermodynamics gradually increased and the melting peak temperature remained unchanged. These data indicate that adding TMC and implementing heat treatment can improve the crystallinity of PLA. These experimental results are consistent with those obtained in Bai's work [38].
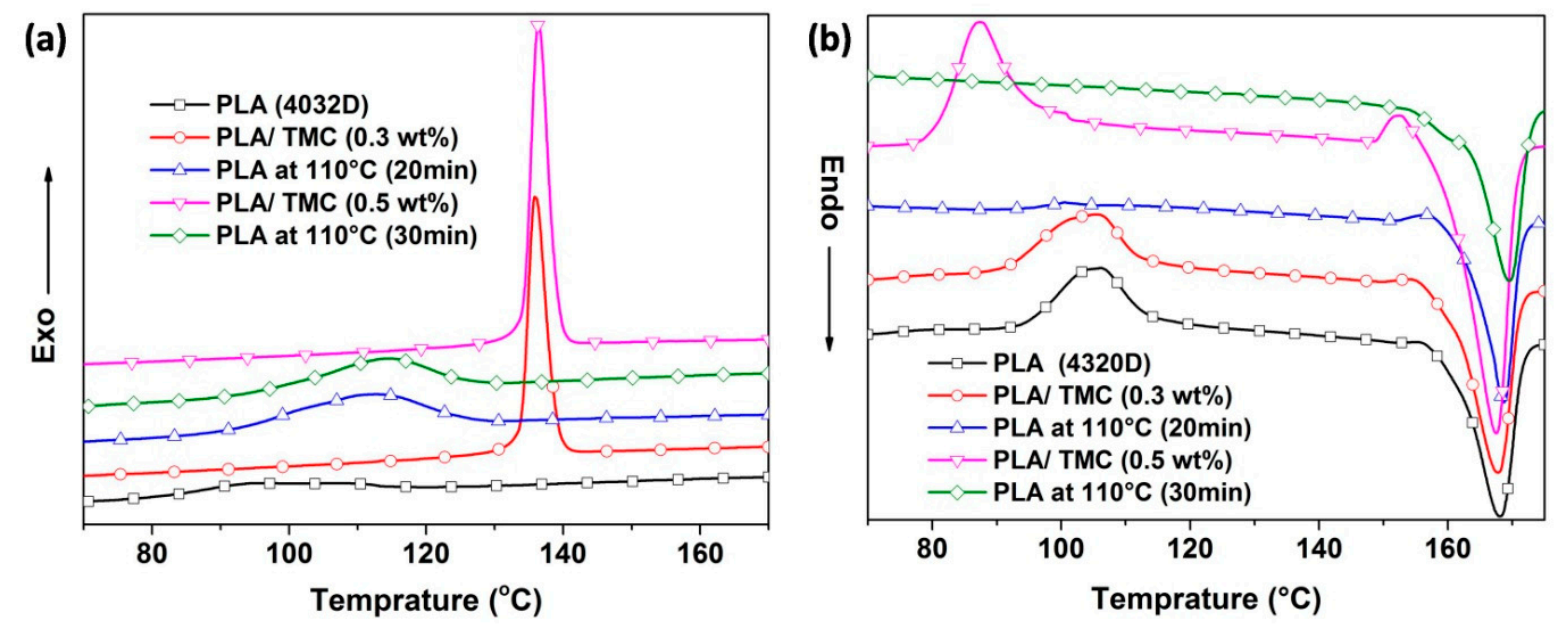

Figure 3. DSC curve of neat PLA, PLA/TMC (0.3 wt $\%$ and $0.5 \mathrm{wt} \%)$ composites and PLA (subjected to heat treatment at $110{ }^{\circ} \mathrm{C}$ for 20 and $30 \mathrm{~min}$ ). (a) Crystallization and (b) melting curves.

Although PLA subjected to 30 min of heat treatment exhibited nearly the same crystallinity as PLA treated with $0.5 \mathrm{wt} \% \mathrm{TMC}$, their HDT values significantly differed. To investigate this difference, the crystallization activation energies of neat PLA and PLA/TMC $(0.5 \mathrm{wt} \%)$ were studied (Figure 4).

Thus, the $\Delta E$ values of nonisothermal crystallization were -255 and $-275 \mathrm{~kJ} \mathrm{~mol}^{-1}$ for neat PLA and PLA/TMC $(0.5 \mathrm{wt} \%)$ composites, respectively. The absolute value of $\Delta E$ for PLA/TMC $(0.5 \mathrm{wt} \%)$ was slightly higher than that of neat PLA, implying that the crystallization capacity of the PLA-MC composites was slower than that of neat PLA. However, the crystallinity of PLA/TMC $(0.5 \mathrm{wt} \%)$ was higher than that of neat PLA. Therefore, TMC acted as a heterogeneous nucleating agent and did not change the energy barrier of the ordered arrangement of the PLA crystal molecular chains. These results were consistent with those obtained in Xu's work [38]. 

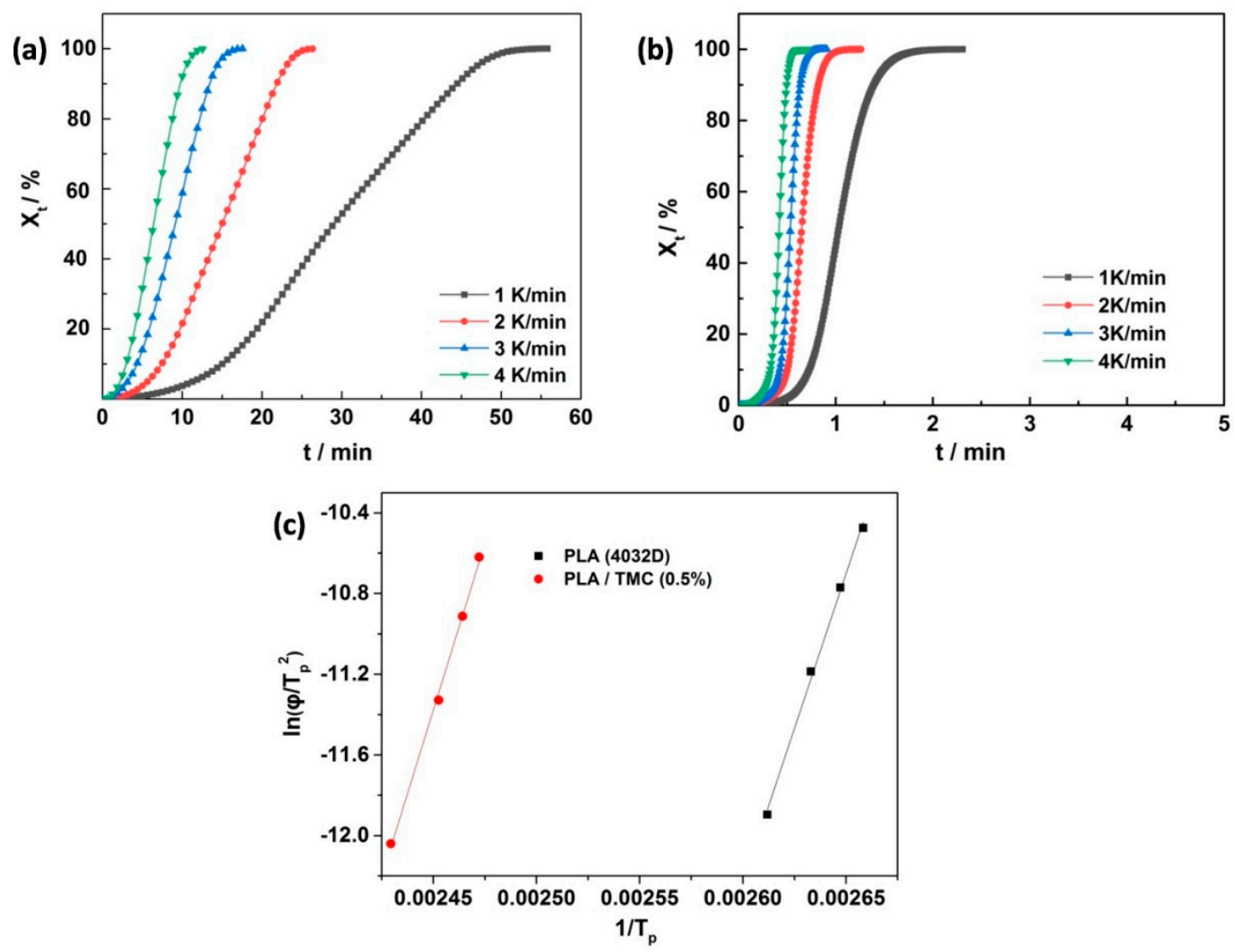

Figure 4. Crystallinity of (a) neat PLA and (b) PLA/TMC (0.5 wt \%) versus crystallization time at varying crystallization rates; (c) Kissinger plots of $\ln \left(\varphi / \mathrm{T}_{\mathrm{p}}{ }^{2}\right)$ for estimating crystallization activation energy.

\subsection{X-ray Diffraction (XRD) Characterization}

Neat PLA, heat-treated PLA and PLA/TMC composites were independently analyzed using XRD, as shown in Figure 5a. All PLA/TMC composites exhibited diffuse diffraction peaks rather than sharp crystal diffraction peaks, indicating incomplete crystallization, which was inconsistent with DSC results. Moreover, PLA heat-treated for 20 and 30 min exhibited sharp crystal diffraction peaks at $2 \theta=16.7^{\circ}, 19.1^{\circ}$ and $22.5^{\circ}$. These data indicate that the degree of crystallinity and reinforcement of PLA were influenced by heat treatment at varying times. According to formula 3 , the crystallinity of PLA heat-treated at $110{ }^{\circ} \mathrm{C}$ for 20 and $30 \mathrm{~min}$ was $25.7 \%$ and $30.0 \%$, respectively. These data indicate that the crystallinity increased as the heating time increased, which was consistent with the DSC result. According to formula 4, the size of the heat-treated PLA crystals was 1.2 and $2.5 \mathrm{~nm}$, respectively. The results of the XRD and DSC experiments show that the addition of TMC could increase the crystallization rate of PLA; however, heat treatment improves the crystallinity of PLA, inducing a more complete PLA crystal. Therefore, a model for adding TMC and implementing heat treatment to improve PLA crystallization was proposed here, as shown in Figure 5b. Neat PLA exhibits low crystallinity and incomplete crystals. With the addition of TMC, more PLA crystals were formed, but the arrangement of the PLA molecular chains was not compact. Post heat treatment of neat PLA, the crystals were more prevalent, molecular chains were arranged more orderly, and thickness of the sheet crystals increased. To confirm our hypothesis, POM experiments were conducted. 

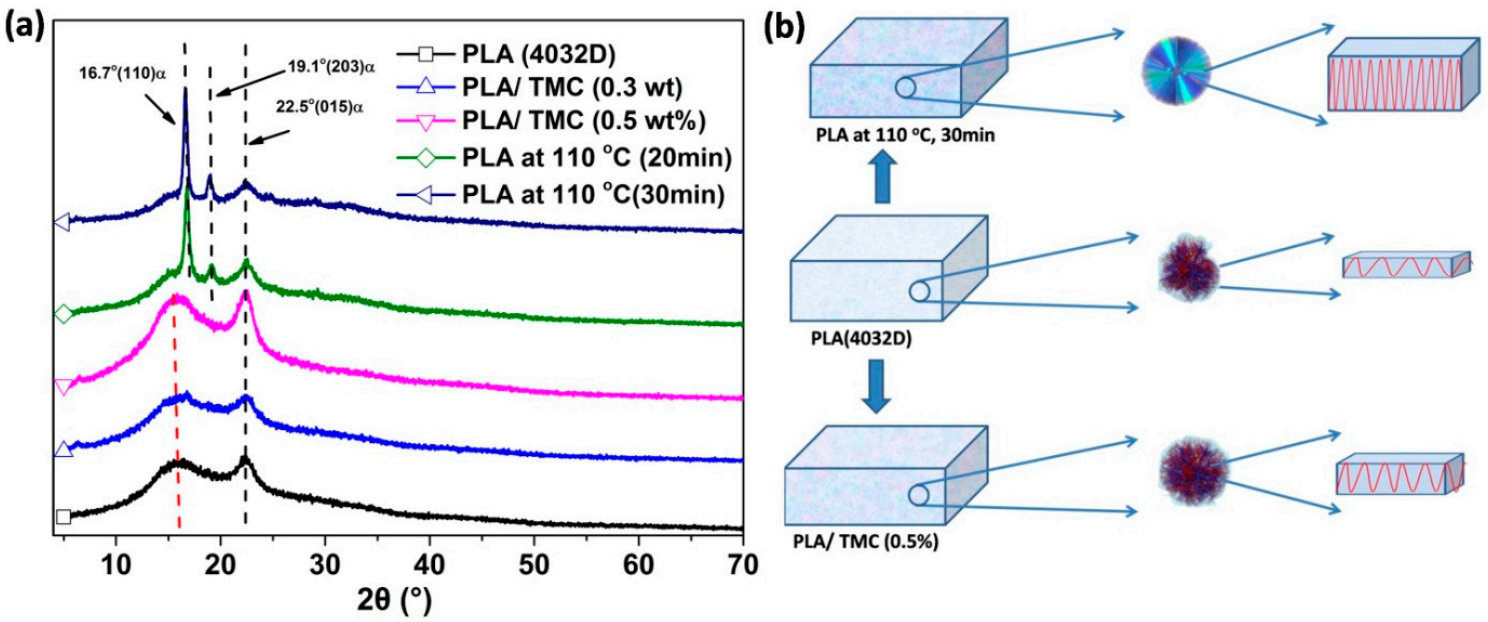

Figure 5. (a) X-ray diffractograms of neat PLA, PLA/TMC (0.3 and $0.5 \mathrm{wt} \%)$ and PLA (subject to heat treatment at $110^{\circ} \mathrm{C}$ for 20 and $\left.30 \mathrm{~min}\right)$; (b) schematic of the crystal morphology of neat PLA, PLA/TMC $(0.5 \mathrm{wt} \%)$ and PLA (subject to heat treatment at $110{ }^{\circ} \mathrm{C}$ for $30 \mathrm{~min}$ ).

\subsection{Polarized Optical Microscopy (POM)}

Figure 6a,e presents the POM micrographs of neat PLA and the PLA/TMC (0.5 wt $\%)$ composite post isothermal crystallization at $130^{\circ} \mathrm{C}$ for $30 \mathrm{~min}$. The observed neat PLA spherulites with a diameter of $\sim 50 \mu \mathrm{m}$ grew completely with the maltese cross. However, after the addition of TMC, the number of PLA spherulites increased and their size decreased. The spherulites became less complete, which may be attributed to spherulite interference. When the temperature of neat PLA decreased from $210{ }^{\circ} \mathrm{C}$ to $30{ }^{\circ} \mathrm{C}$ at a rate of $10{ }^{\circ} \mathrm{C} \mathrm{min}-1$, the spherulites of neat PLA were few in number, but large in size; these spherulites increased after $30 \mathrm{~min}$ of heat treatment. Conversely, the spherulites of PLA/TMC $(0.5 \mathrm{wt} \%)$ the composite increased in number and decreased in size; further, the spherulites became complete after $30 \mathrm{~min}$ of heat treatment. The above results are consistent with the XRD analysis.
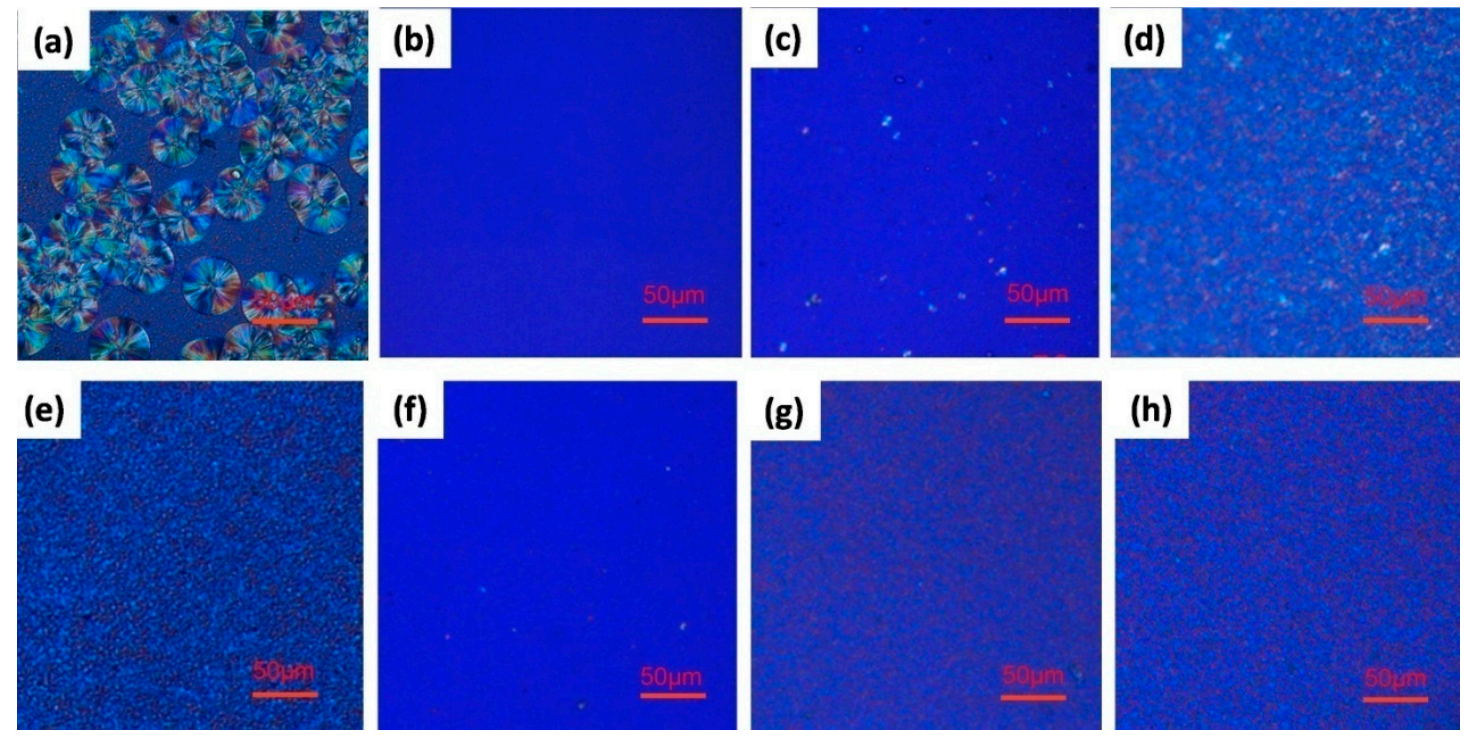

Figure 6. POM results of PLA and PLA/TMC (0.5 wt\%): (a) PLA (4032D) heated at $130{ }^{\circ} \mathrm{C}$ for $30 \mathrm{~min}$, (b) PLA (4032D) heated at $210^{\circ} \mathrm{C}$ for $10 \mathrm{~min}$, (c) PLA (4032D) heated at $30^{\circ} \mathrm{C}$ from $210^{\circ} \mathrm{C}$ at a rate of $10{ }^{\circ} \mathrm{C} \mathrm{min}-1$, (d) PLA (4032D) heated at $110{ }^{\circ} \mathrm{C}$ for $30 \mathrm{~min}$ from $30{ }^{\circ} \mathrm{C}$ at a rate of $10{ }^{\circ} \mathrm{C} \mathrm{min}^{-1}$, (e) PLA/TMC $(0.5 \mathrm{wt} \%)$ heated at $130{ }^{\circ} \mathrm{C}$ for $30 \mathrm{~min}$, (f) PLA/TMC $(0.5 \mathrm{wt} \%)$ heated at $210{ }^{\circ} \mathrm{C}$ for $10 \mathrm{~min}$, (g) PLA/TMC $(0.5 \mathrm{wt} \%)$ heated at $30^{\circ} \mathrm{C}$ from $210^{\circ} \mathrm{C}$ at a rate of $10^{\circ} \mathrm{C} \mathrm{min}-1$ and (h) PLA/TMC $(0.5 \mathrm{wt} \%)$ heated at $110^{\circ} \mathrm{C}$ for $30 \mathrm{~min}$ from $30^{\circ} \mathrm{C}$ at a rate of $10^{\circ} \mathrm{C} \mathrm{min}^{-1}$. 


\section{Conclusions}

Conclusively, we optimized the crystallinity of PLA and increased the HDT of PLA by adding a nucleating agent and implementing heat treatment. The crystallinity of neat PLA was $11.7 \%$ and its HDT was $53.4^{\circ} \mathrm{C}$. The crystallinity of PLA treated at $110^{\circ} \mathrm{C}$ for $30 \mathrm{~min}$ was nearly the same as that of PLA/TMC (0.5 wt\%); however, the HDT of PLA treated at $110{ }^{\circ} \mathrm{C}$ for $30 \mathrm{~min}$ was $72{ }^{\circ} \mathrm{C}$ higher than that of PLA/TMC (0.5 wt\%). The morphology of the PLA crystal was studied by XRD and POM. Results indicated that with the same crystallinity, the crystal obtained via heat treatment was more complete than the PLA/TMC $(0.5 \mathrm{wt} \%)$ composite. Therefore, it was concluded that the crystallization morphology of PLA significantly affected its heat resistance. The findings of this study are therefore significant for examining the relationship between crystallinity, crystallization morphology and heat resistance.

Author Contributions: Y.L. and J.Y. conceived and designed the experiments; S.J. and Y.L. performed the experiments; W.Y. and M.H. analyzed the data; J.Q. and S.Q. contributed reagents/materials/analysis tools; Y.L. and S.J. wrote the paper. All authors have read and agreed to the published version of the manuscript.

Funding: This research was funded by the National Natural Science Foundation of China (grant 51663006 and 21266005), Guizhou Postgraduate Research Fund (Guizhou teaches together YJSCXJH [2019] 004) and Guizhou Province Science and Technology Program Project (grant [2017] 5788, [2017] 5623 and [2017] 1091).

Conflicts of Interest: The authors declare no conflict of interest.

\section{References}

1. Bhasney, S.M.; Bhagabati, P.; Kumar, A.; Katiyar, V. Morphology and crystalline characteristics of polylactic acid [PLA]/linear low density polyethylene [LLDPE]/microcrystalline cellulose [MCC] fiber composite. Compos. Sci. Technol. 2019, 171, 54-61. [CrossRef]

2. Wang, F.; Sun, Z.; Yin, J.; Xu, L. Preparation, characterization and properties of porous PLA/PEG/Curcumin composite nanofibers for antibacterial application. Nanomaterials (Basel) 2019, 9, 508. [CrossRef] [PubMed]

3. Li, Z.; Muiruri, J.K.; Thitsartarn, W.; Zhang, X.; Tan, B.H.; He, C. Biodegradable silica rubber core-shell nanoparticles and their stereocomplex for efficient PLA toughening. Compos. Sci. Technol. 2018, 159, 11-17. [CrossRef]

4. Yeo, J.C.C.; Muiruri, J.K.; Tan, B.H.; Thitsartarn, W.; Kong, J.; Zhang, X.; Li, Z.; He, C. Biodegradable PHB-rubber copolymer toughened PLA green composites with ultrahigh extensibility. ACS Sustain. Chem. Eng. 2018, 6, 15517-15527. [CrossRef]

5. Li, C.; Guo, J.; Jiang, T.; Zhang, X.; Xia, L.; Wu, H.; Guo, S.; Zhang, X. Extensional flow-induced hybrid crystalline fibrils (shish) in CNT/PLA nanocomposite. Carbon 2018, 129, 720-729. [CrossRef]

6. Zhang, L.; Lv, S.; Sun, C.; Wan, L.; Tan, H.; Zhang, Y. Effect of MAH-g-PLA on the properties of wood fiber/polylactic acid composites. Polymers-Basel 2017, 9, 591. [CrossRef]

7. Del Rosario Salazar-Sánchez, M.; Campo-Erazo, S.D.; Villada-Castillo, H.S.; Solanilla-Duque, J.F. Structural changes of cassava starch and polylactic acid films submitted to biodegradation process. Int. J. Biol. Macromol. 2019, 129, 442-447. [CrossRef] [PubMed]

8. Tabi, T.; Sajo, I.E.; Szabo, F.; Luyt, A.S.; Kovacs, J.G. Crystalline structure of annealed polylactic acid and its relation to processing. Express Polym. Lett. 2010, 4, 659-668. [CrossRef]

9. Girdthep, S.; Sankong, W.; Pongmalee, A.; Saelee, T.; Punyodom, W.; Meepowpan, P.; Worajittiphon, P. Enhanced crystallization, thermal properties, and hydrolysis resistance of poly(l-lactic acid) and its stereocomplex by incorporation of graphene nanoplatelets. Polym. Test. 2017, 61, 229-239. [CrossRef]

10. Peelman, N.; Ragaert, P.; Ragaert, K.; Erkoç, M.; Van Brempt, W.; Faelens, F.; Devlieghere, F.; De Meulenaer, B.; Cardon, L. Heat resistance of biobased materials, evaluation and effect of processing techniques and additives. Polym. Eng. Sci. 2018, 58, 513-520. [CrossRef]

11. Zhang, H.; Ming, R.; Yang, G.; Li, Y.; Li, Q.; Shao, H. Influence of alkali treatment on flax fiber for use as reinforcements in polylactide stereocomplex composites. Polym. Eng. Sci. 2015, 55, 2553-2558. [CrossRef]

12. Dhar, P.; Katiyar, V. Thermal degradation kinetics of polylactic acid/acid fabricated cellulose nanocrystal based bionanocomposites. Int. J. Biol. Macromol. 2017, 104, 827-836. 
13. Wang, L.; Wang, Y.; Huang, Z.; Weng, Y. Heat resistance, crystallization behavior, and mechanical properties of polylactide/nucleating agent composites. Mater. Design (1980-2015) 2015, 66, 7-15. [CrossRef]

14. Liu, Y.; He, M.; Yan, W.; Zhang, D.; Zhao, Q.; Qin, S.; Yu, J. P(N-phenylmaleimide-alt-styrene) as a heat-resistant agent in the application of nylon 6. J. Appl. Polym. Sci. 2019, 136, 47689. [CrossRef]

15. Liu, Y.; He, M.; Zhang, D.; Zhao, Q.; Li, Y.; Qin, S.; Yu, J. P(N-Phenylmaleimide-Alt-Styrene) introduced with 4-carboxyl and its effect on the heat deflection temperature of nylon 6. Materials 2018, 11, 2330. [CrossRef]

16. Rigolin, T.R.; Takahashi, M.C.; Kondo, D.L.; Bettini, S.H.P. Compatibilizer acidity in Coir-Reinforced PLA composites: Matrix degradation and composite properties. J. Polym. Environ. 2019, 27, 1096-1104. [CrossRef]

17. Kumar, A.; Tumu, V.R.; Ray Chowdhury, S.; Ramana Reddy, S.V.S. A green physical approach to compatibilize a bio-based poly (lactic acid)/lignin blend for better mechanical, thermal and degradation properties. Int. J. Biol. Macromol. 2019, 121, 588-600. [CrossRef]

18. Spinella, S.; Lo Re, G.; Liu, B.; Dorgan, J.; Habibi, Y.; Leclère, P.; Raquez, J.; Dubois, P.; Gross, R.A. Polylactide/cellulose nanocrystal nanocomposites: Efficient routes for nanofiber modification and effects of nanofiber chemistry on PLA reinforcement. Polymer 2015, 65, 9-17. [CrossRef]

19. Bledzki, A.K.; Franciszczak, P.; Meljon, A. High performance hybrid PP and PLA biocomposites reinforced with short man-made cellulose fibres and softwood flour. Compos. Part A Appl. Sci. Manuf. 2015, 74, 132-139. [CrossRef]

20. Luo, H.; Zhang, C.; Xiong, G.; Wan, Y. Effects of alkali and alkali/silane treatments of corn fibers on mechanical and thermal properties of its composites with polylactic acid. Polym. Compos. 2016, 37, 3499-3507. [CrossRef]

21. Tábi, T.; Wacha, A.F.; Hajba, S. Effect of D-lactide content of annealed poly(lactic acid) on its thermal, mechanical, heat deflection temperature, and creep properties. J. Appl. Polym. Sci. 2018, 136, 47103. [CrossRef]

22. Chen, P.; Lian, H.; Shih, Y.; Chen-Wei, S.; Jeng, R. Preparation, characterization and crystallization kinetics of Kenaf fiber/multi-walled carbon nanotube/polylactic acid (PLA) green composites. Mater. Chem. Phys. 2017, 196, 249-255. [CrossRef]

23. Spinella, S.; Samuel, C.; Raquez, J.; McCallum, S.A.; Gross, R.; Dubois, P. Green and efficient synthesis of dispersible cellulose nanocrystals in biobased polyesters for engineering applications. ACS Sustain. Chem. Eng. 2016, 4, 2517-2527. [CrossRef]

24. Burzic, I.; Pretschuh, C.; Kaineder, D.; Eder, G.; Smilek, J.; Másilko, J.; Kateryna, W. Impact modification of PLA using biobased biodegradable PHA biopolymers. Eur. Polym. J. 2019, 114, 32-38. [CrossRef]

25. Garcia-Campo, M.J.; Quiles-Carrillo, L.; Sanchez-Nacher, L.; Balart, R.; Montanes, N. High toughness poly(lactic acid) (PLA) formulations obtained by ternary blends with poly(3-hydroxybutyrate) (PHB) and flexible polyesters from succinic acid. Polym. Bull. 2019, 76, 1839-1859. [CrossRef]

26. Bai, Z.; Dou, Q. Rheology, morphology, crystallization behaviors, mechanical and thermal properties of poly(lactic acid)/polypropylene/maleic anhydride-graftedpolypropylene blends. J. Polym. Environ. 2018, 26, 959-969. [CrossRef]

27. Gonzalez-Garzon, M.; Shahbikian, S.; Huneault, M.A. Properties and phase structure of melt-processed PLA/PMMA blends. J. Polym. Res. 2018, 25, 58. [CrossRef]

28. Yuryev, Y.; Mohanty, A.K.; Misra, M. Novel biocomposites from biobased PC/PLA blend matrix system for durable applications. Compos. Part B Eng. 2017, 130, 158-166. [CrossRef]

29. Guo, X.; Zhang, J.; Huang, J. Poly(lactic acid)/polyoxymethylene blends: Morphology, crystallization, rheology, and thermal mechanical properties. Polymer 2015, 69, 103-109. [CrossRef]

30. Tábi, T.; Hajba, S.; Kovács, J.G. Effect of crystalline forms ( $\alpha^{\prime}$ and $\alpha$ ) of poly(lactic acid) on its mechanical, thermo-mechanical, heat deflection temperature and creep properties. Eur. Polym. J. 2016, 82, 232-243. [CrossRef]

31. Yu, T.; Jiang, N.; Li, Y. Study on short ramie fiber/poly(lactic acid) composites compatibilized by maleic anhydride. Compos. Part A Appl. Sci. 2014, 64, 139-146. [CrossRef]

32. Wang, G.; Zhang, D.; Li, B.; Wan, G.; Zhao, G.; Zhang, A. Strong and thermal-resistance glass fiber-reinforced polylactic acid (PLA) composites enabled by heat treatment. Int. J. Biol. Macromol. 2019, 129, 448-459. [CrossRef] [PubMed]

33. Pan, H.; Kong, J.; Chen, Y.; Zhang, H.; Dong, L. Improved heat resistance properties of poly(l-lactide)/basalt fiber biocomposites with high crystallinity under forming hybrid-crystalline morphology. Int. J. Biol. Macromol. 2019, 122, 848-856. [CrossRef] [PubMed] 
34. Lin, L.; Deng, C.; Lin, G.; Wang, Y. Super toughened and high heat-resistant poly(lactic acid) (PLA)-based blends by enhancing interfacial bonding and PLA phase crystallization. Ind. Eng. Chem. Res. 2015, 54, 5643-5655. [CrossRef]

35. Xu, T.; Wang, Y.; Han, Q.; He, D.; Li, Q.; Shen, C. Nonisothermal crystallization kinetics of poly(lactic acid) nucleated with a multiamide nucleating agent. J. Macromol. Sci. Part B 2014, 53, 1680-1694. [CrossRef]

36. Shen, X.; Hu, W.; Russell, T.P. Measuring the degree of crystallinity in semicrystalline regioregular poly(3-hexylthiophene). Macromolecules 2016, 49, 4501-4509. [CrossRef]

37. Li, X.; Dong, F.; Zhang, L.; Xu, Q.; Zhu, X.; Liang, S.; Hu, L.; Xie, H. Cellulosic protic ionic liquids hydrogel: A green and efficient catalyst carrier for Pd nanoparticles in reduction of 4-nitrophenol in water. Chem. Eng. J. 2019, 372, 516-525. [CrossRef]

38. Xue, B.; Guo, D.; Bao, J. Effect of sebacate benzohydydrazide on heat-resistance property of poly(lactic acid). Polym. Mate. Sci. Eng. 2014, 30, 59-63.

39. Tsuji, H.; Ikada, Y. Properties and morphologies of L-lactide): 1. Annealing condition effects on properties and morphologie poly(L-lactide). Polymer 1995, 36, 2709-2716. [CrossRef]

40. Han, Q.; Wang, Y.; Shao, C.; Zheng, G.; Li, Q.; Shen, C. Nonisothermal crystallization kinetics of biodegradable poly (lactic acid)/zinc phenylphosphonate composites. J. Compos. Mater. 2014, 48, 2737-2746. [CrossRef]

41. Wu, N.; Wang, H. Effect of Zinc Phenylphosphonate on the Crystallization Behavior of Poly(L-lactide). J. Appl. Polym. Sci. 2013, 130, 2744-2752. [CrossRef]

(C) 2020 by the authors. Licensee MDPI, Basel, Switzerland. This article is an open access article distributed under the terms and conditions of the Creative Commons Attribution (CC BY) license (http://creativecommons.org/licenses/by/4.0/). 